\title{
Poisonings After a Hurricane: Lessons From the New Jersey Poison Information and Education System (NJPIES) During and Following Hurricane Sandy
}

\author{
Susan B. German, MPH; Pauline A. Thomas, MD; Bruce Ruck, PharmD; \\ Elizabeth G. Marshall, PhD; Amy L. Davidow, PhD
}

\section{ABSTRACT}

Objective: Hurricane Sandy made landfall in New Jersey on October 29, 2012, resulting in widespread power outages and gasoline shortages. These events led to potentially toxic exposures and the need for information related to poisons/toxins in the environment. This report characterizes the New Jersey Poison Information and Education System (NJPIES) call patterns in the days immediately preceding, during, and after Hurricane Sandy to identify areas in need of public health education and prevention.

Methods: We examined NJPIES case data from October through December 2012. Most Sandy-related calls had been coded as such by NJPIES staff. Additional Sandy-related cases were identified by performing a case narrative review. Descriptive analyses were performed for timing, case frequencies, exposure substances, gender, caller site, type of information requests, and other data.

Results: The most frequent Sandy-related exposures were gasoline and carbon monoxide (CO). Gasoline exposure cases were predominantly males and $\mathrm{CO}$ exposure cases, females $(P<0.0001)$. Other leading reasons for Sandy-related calls were poison information, food poisoning/spoilage information, and water contamination.

Conclusions: This analysis identified the need for enhanced public health education and intervention to improve the handling of gasoline and encourage the proper use of gasoline-powered generators and cleaning and cooking equipment, thus reducing toxic exposures.

Key Words: carbon monoxide, gasoline, hurricane

$\mathrm{E}$ very year, from June through November, hurricanes threaten and often devastate areas of the eastern US seacoast, the Gulf Coast, and Caribbean islands. With successive hurricanes, acute gasoline and carbon monoxide (CO) poisonings persistently accompany the direct effects of wind and water on human health. ${ }^{1}$

Following hurricanes, the most frequent serious concerns called in to poison control centers are $\mathrm{CO}$ and gasoline exposures. ${ }^{1-3}$ In a Texas study, during the evacuation and landfall periods, the mean daily call volume for gasoline exposure significantly increased from the baseline (pre-evacuation) period. During post-evacuation, the mean daily call volume significantly increased from the baseline period for both $\mathrm{CO}$ and gasoline. ${ }^{2}$

Carbon monoxide poisoning is a leading preventable cause of morbidity and mortality in disaster-affected areas. Generators have been reported as the primary exposure source for over $80 \%$ of fatal cases and more than half of non-fatal cases. Most CO cases occurred within 3 days of disaster onset. ${ }^{3}$ Less has been reported about gasoline exposure and poisoning, but loss of power often results in handling gasoline for generators or siphoning gasoline from fuel tanks.

On October 29, 2012, Hurricane Sandy made landfall near Atlantic City, New Jersey, wreaking damage from flooding, waves, and wind. There were widespread power outages, evacuations, and gasoline shortages.

Among a total of 10806 calls to the New Jersey Poison Information and Education System (NJPIES) from October 26, when evacuation began, through December 2012, 498 calls from the public and professionals were deemed Sandy-related. Sandy-related case volumes peaked from October 30 through November 4.

The 2 most frequent Sandy-related exposures were gasoline exposure $(\mathrm{n}=160$ [32.1\%]) and $\mathrm{CO}$ exposure $(n=100$ [20.1\%]), which followed the pattern seen after hurricanes such as Katrina and Wilma in 2005, Ike in 2008, and Irma in 2017., 1,4 Carbon monoxide and gasoline exposures accounted for most calls.

Figure 1 shows the timing of the calls for $\mathrm{CO}$ and gasoline. Calls with either of these exposures peaked on 
FIGURE 1

Calls to NJPIES for Carbon Monoxide and Gasoline Exposures, October 15 - December 31, 2012.

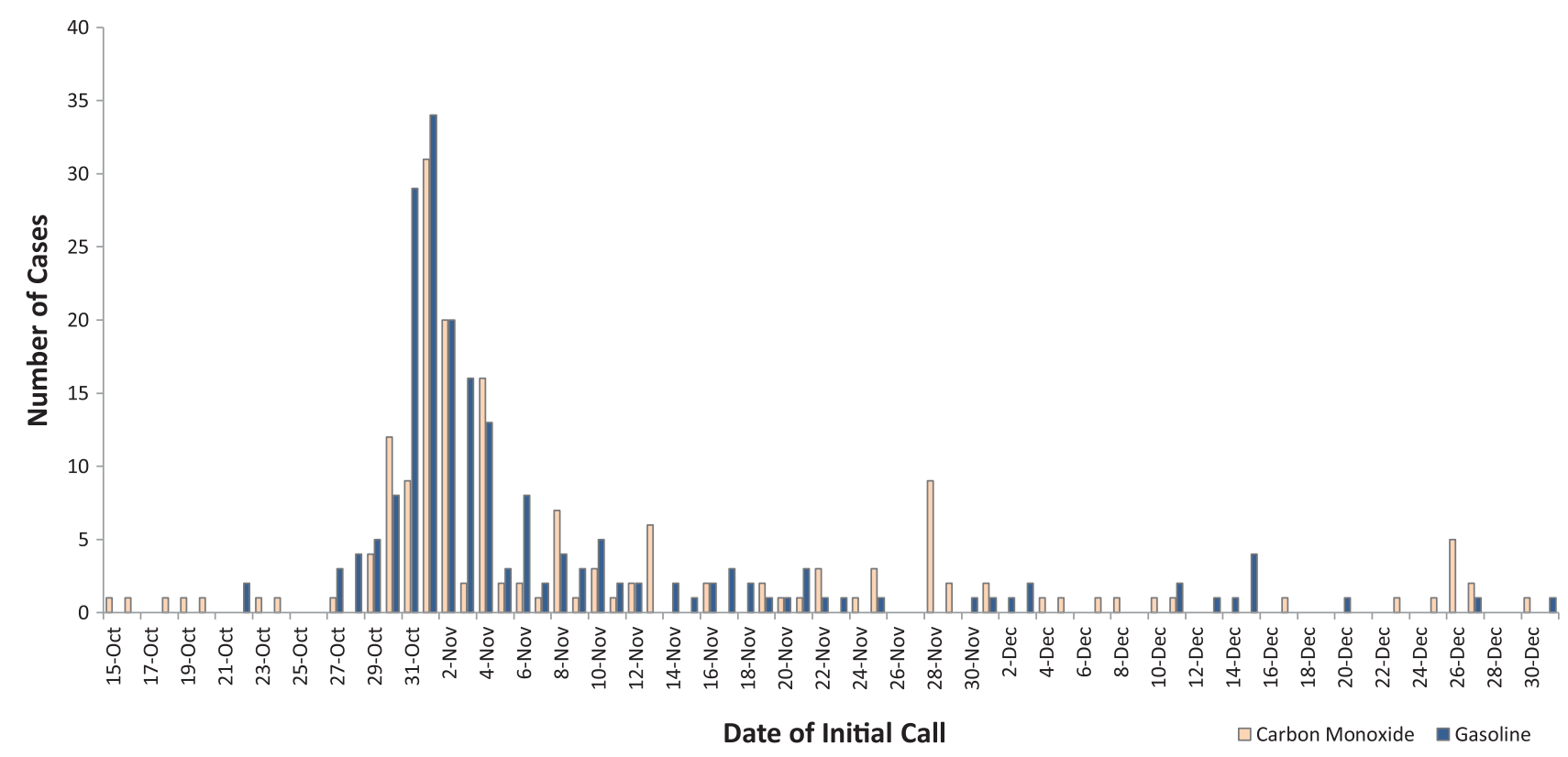

November 1, which was 3 days after landfall. The source of most $(64 \%)$ calls about CO exposure was a health care facility, whereas only $6.3 \%$ of gasoline calls were initiated in this manner. Excluding information-seeking calls and restricting to calls reporting an actual exposure $(\mathrm{n}=380)$, gasoline exposure calls were predominantly males $(86.9 \%)$ and $\mathrm{CO}$ exposure calls, females $(61 \%)(P<0.0001)$.

It was surprising to us that, after more recent storms in 2017 and 2018, storm-related $\mathrm{CO}$ poisoning continued to occur, despite 3 decades of prevention efforts. ${ }^{4-6}$ Research has shown that, despite public health messaging and warnings from national, state, and regional entities on the dangers of $\mathrm{CO}$ and gasoline exposures, these exposures still occur. ${ }^{1,2}$

NJPIES provided essential guidance and information to health care facilities and individuals during Hurricane Sandy. A Google search of "How to siphon gas" identified 20500 results, suggesting that the dangers of this activity are still not widely known. ${ }^{7}$ The need remains for enhanced prevention and intervention strategies, in addition to ongoing public education on the proper handling of fuel and use of gasoline-powered generators.

\section{About the Authors}

Rutgers Cancer Institute of New Jersey; Rutgers New Jersey Medical School (affiliation during the time of this writing), Newark, NJ (Ms German); Rutgers New Jersey Medical School, Newark, NJ (Dr Thomas); New Jersey Poison Information and Education System, Rutgers New Jersey Medical School,
Newark, NJ (Dr Ruck) and Rutgers School of Public Health, Piscataway, NJ (Drs Marshall, Davidow)

Correspondence and reprint requests to Susan B. German, (e-mail: susan.german@ rutgers.edu).

\section{Acknowledgments}

The authors thank G. Raul Rego of NJPIES for preparing and providing NJPIES data for this project.

\section{Financial Support}

This project was funded by a grant from the Centers for Disease Control and Prevention.

\section{Conflict of Interest Statement}

The authors have no conflicts of interest to declare.

\section{REFERENCES}

1. Centers for Disease Control and Prevention (CDC). Monitoring poison control center data to detect health hazards during hurricane season - Florida, 2003-2005. MMWR Morb Mortal Wkly Rep. 2006;55(15):426-428.

2. Forrester MB. Impact of Hurricane Ike on Texas poison center calls. Disaster Med Public Health Prep. 2009;3(3):151-157.

3. Iqbal S, Clower JH, Hernandez SA, et al. A review of disaster-related carbon monoxide poisoning: surveillance, epidemiology, and opportunities for prevention. Am J Public Health. 2012;102(10):1957-1963.

4. Mulay PR, Ramadugu K, Atrubin D, et al. Utilizing syndromic surveillance for Hurricane Irma-related CO poisonings in Florida. J Public Health Inform. 2019;11(1):e451. doi: 10.5210/ojphi.v11i1.9940. 
5. Henretig FM, Calello DP, Burns MM, et al. Predictable, preventable, and deadly: epidemic carbon monoxide poisoning after storms. Am J Public Health. 2018;108(10):1320-1321.

6. Centers for Disease Control and Prevention (CDC). Poison Center and Public Health Collaborations Community of Practice (PC PH CoP) newsletter. Disaster response: an intersection of poison control and public health. 2019. https://www.cdc.gov/nceh/hsb/chemicals/pdfs/PoisonCPHCCP_ Newsletter_Spr2019_508.pdf. Accessed November 17, 2019.

7. Jalopnik. How to siphon gas. November 2, 2012. https://jalopnik.com/howto-siphon-gas-5956062. Accessed November 21, 2019. 